\title{
26 Research Square \\ Smoking Cessation in Head and Neck Cancer Patients: A Mixed Methods Study
}

Justin R Smith

James Cook University College of Medicine and Dentistry

Torres Woolley

James Cook University College of Medicine and Dentistry

Amy Brown

Townsville Hospital

Venkat Vangaveti

James Cook University College of Medicine and Dentistry

Madhavi Chilkuri ( $\square$ madhavi.chilkuri@health.qld.gov.au )

Townsville Hospital

Research article

Keywords: Head and neck cancer; smoking cessation; mixed methods; smoking behaviours

Posted Date: March 4th, 2020

DOl: https://doi.org/10.21203/rs.3.rs-15997/v1

License: (a) This work is licensed under a Creative Commons Attribution 4.0 International License.

Read Full License 


\section{Abstract}

Background This study investigated the smoking behaviours and cessation rates of head and neck cancer patients and explored the barriers and facilitators to cessation. Methods A mixed methods sequential explanatory design was utilised. The quantitative data was collected through surveys prior to treatment commencement. The current smokers were followed up after treatment to determine their smoking status. One-on-one, semi-structured interviews were then conducted. Results A total of 64 participants were recruited. Participants who were current smokers were more likely to live in a rural location ( $p=0.015)$, have lower education $(p=0.047)$, and report reduced social and family well-being ( $p$ $=0.005$ ) when compared with those who were former or never smokers. The 7-day point prevalence cessation rate was $72 \%$ at 1 -month follow-up and $67 \%$ at 3 months, while continuous smoking cessation was $54 \%$ at 1 month and $42 \%$ at 3 months. Participants who continued smoking were found to consume more alcohol $(p=0.032)$ and have higher psychological distress $(p=0.052)$. Qualitative analysis revealed 5 key themes associated with smoking cessation: the teachable moment of a cancer diagnosis and treatment, willpower and cessation aids, psychosocial environment, relationship with alcohol and marijuana, and health knowledge and beliefs surrounding smoking and cancer. Conclusion This study demonstrates that the majority of head and neck cancer patients are able to achieve smoking cessation, but relapses are common. Future cessation programs should be comprehensive, sustained and address co-morbid factors such as alcohol, marijuana and depression.

\section{Background}

Cancers of the head and neck region (HNC) occur in the oral cavity, oropharynx, hypopharynx, nasopharynx and larynx. Approximately $90 \%$ of these cancers are squamous cell carcinomas (HNSCC). The major risk factors for HNSCC are tobacco and alcohol use [1-3], with human papillomavirus (HPV) infection a causative agent in a subset of patients [2]. Prognosis is dependent upon the stage, location and HPV status of the tumour [4-6]. Continued smoking after diagnosis has also been demonstrated to be a poor prognostic factor. A meta-analysis concluded that patients undergoing radiotherapy who continued smoking had approximately twice the risk of mortality and locoregional failure [7]. Patients who continue smoking have also been found to have a higher risk of second primary malignancies [8] and a lower quality of life [9]. Encouragingly, studies have determined that motivation and interest in smoking cessation is increased after a diagnosis of cancer, particularly those that are related to smoking, such as head and neck cancer [10]. However, at least one third of patients with head and neck cancer still continue to smoke after their diagnosis [11]. The optimal intervention to encourage smoking cessation remains unclear. A recent systematic review of cessation interventions in head and neck cancer patients concluded that there was limited evidence on the optimal cessation strategy [11]. There have been no mixed-methods and only one qualitative study that investigated smoking behaviours or cessation in head and neck cancer patients, and these patients were in longer-term follow-up (beyond 12 months) [12].

Using a mixed-methods approach, this study aimed to investigate the smoking behaviours and cessation rates of newly diagnosed head and neck cancer patients and identify barriers and facilitators to achieving 
smoking cessation.

\section{Methods}

\section{Study Design}

An explanatory sequential mixed methods design (Figure 1) was used. Preliminary data from a 5-year prospective single institution cohort study commenced in February 2018 (ACTRN12618000165280) was utilised for the quantitative component to determine the demographic and other factors that are associated with smoking cessation. After analysis of this data, the qualitative component was conducted using a basic descriptive design to identify and explore in-depth the barriers and facilitators to smoking cessation. Ethics approval for this study was obtained from the Townsville Hospital and Health Service Human Research Ethics Committee (HREC/17/QTHS/223).

\section{Study Population}

The Townsville Hospital (TTH) is a tertiary referral hospital located in North Queensland, Australia. The region of North Queensland extends from Mackay to the Torres Strait, with patients often having to travel significant distances (up to $800 \mathrm{~km}$ ) for treatment given the geographic nature of this region.

\section{Participant Selection}

Patients with head and neck cancer squamous cell carcinoma who presented to TTH and met the eligibility criteria were invited to participate in the study prior to the commencement of their treatment. Patients were screened at the weekly multidisciplinary meeting and considered eligible if they were undergoing curative treatment for histologically proven squamous cell carcinomas of the oral cavity, nasopharynx, oropharynx, hypopharynx, larynx, nasal cavity or paranasal sinuses. Participants also had to have no distant metastases, an ECOG performance status of $0-1$, have no previous radiation therapy to the head and neck region and be disease free from a prior invasive malignancy for three years or greater. If deemed suitable for curative treatment, patients with synchronous malignancies were also included.

\section{Smoking Cessation}

Based upon baseline smoking status, the patients were first divided into two groups - current smokers and former/never smokers. Current smokers were defined as those who had smoked in the 30 days prior to their head and neck cancer diagnosis. Former smokers were those who had quit more than 1 month prior to their diagnosis, while never smokers were patients that had smoked less than 100 cigarettes in their lifetime. An initial quantitative analysis was performed in this overall group to identify any demographic differences between current smokers and former/never smokers, and then the current smokers group became the focus for the remainder of the study.

Smoking cessation advice is given as standard of care to all head and neck cancer patients at TTH by the treating team, irrespective of involvement in the study. This involves brief counselling, referral to Quitline, 
and provision of nicotine replacement therapy. The smoking cessation support is provided by a clinical care nurse and occurs over the 2-3 week period prior to treatment commencement, and then as required in the follow-up period. This is balanced with the nurse's other clinical commitments, which means that the follow-up appointments are not structured. Included in the cessation support is exhaled carbon monoxide testing, which provides biochemical verification of smoking status and is used as a motivational tool.

In this study, smoking cessation was defined at 1 and 3 month follow-up periods as both a continuous and a 7-day point prevalence rate. Continuous abstinence was defined as smoking cessation from commencement of treatment until the follow up period, with not a single relapse, while 7-day point prevalence rate was defined as not smoking in the 7 days prior to the follow up period.

\section{Data Collection}

\section{Quantitative Surveys}

Patients were given an initial questionnaire prior to treatment commencement (Supplementary 1) which included information on their past education, a validated Quality of Life (FACT-H\&N) [13], smoking behaviours, cessation attempts, alcohol usage (AUDIT-C) [14] and current psychological distress (K10) [15]. The smoking behaviour questions also allowed for assessment of the stage of change of each current smoker as per the transtheoretical model [16].

During their treatment period, patients who were current smokers were asked to complete a brief survey asking the number of cigarettes smoked in the last week. Patients were then followed up at 1 and 3 months after the completion of their treatment for follow-up questionnaires. This questionnaire included details on their Quality of Life (FACT-H\&N), smoking status (for current smokers) and alcohol use (AUDITC). Apart from smoking status of the current smokers, the data from these follow-up surveys did not form part of this analysis but will be included in the results of the 5-year prospective study.

\section{Carbon Monoxide Reading}

Patients identified as current smokers had a baseline carbon monoxide reading performed at the multidisciplinary meeting or at their radiotherapy simulation session. This reading was then repeated on the first day of treatment commencement (either radiotherapy or surgery). For patients undergoing radiotherapy, a carbon monoxide reading was also conducted at least three times during their treatment course. Another reading was completed at 1 and 3 month follow-up if the participant was present in Townsville for their review. Smoking cessation was defined as a CO reading of $\leq 8 \mathrm{ppm}$ [17]. Some patients had tele-link review appointments, which meant a carbon monoxide reading was not possible.

\section{Qualitative Interviews}

Fifteen, one-on-one, semi-structured interviews were performed with patients who were defined as current smokers in their baseline surveys, and who were at least 1-month post completion of their treatment. Interviews were conducted in person $(n=11)$ or over the phone $(n=4)$. 
Interview questions explored participants' attitudes towards their smoking and factors that were facilitators or barriers towards achieving cessation (Supplementary 2). The interviews were conducted by a final year medical student (JS) and a university academic with research experience (TW), neither of whom were involved in the participants' clinical care. The one-on-one interviews were recorded and then transcribed into a Microsoft word document.

Analysis

\section{Quantitative}

Responses from the surveys were coded and entered into the computerised statistical package for social sciences (SPSS) release 25 for Windows (https://www.ibm.com/au-en/analytics/spss-statisticssoftware). An analysis was initially performed with the 2 groups - current smokers and former/never smokers, followed by a further analysis just on the current smoker group, between those who continued smoking and those who ceased smoking (as per the 3-month continuous abstinence definition).

To identify potential statistical associations between the categorical variable 'smoking groups' and all independent variables, Mann-Whitney $U$ tests (median and interquartile range reported), $T$ tests (mean and standard deviation reported), and Chi Square or Fisher's exact tests (percentages reported) were used, as appropriate. Statistical associations were considered significant if the $p$-value was $<0.05$.

\section{Qualitative}

The transcripts were imported into NVivo version 12 (https://www.qsrinternational.com/nvivo/home). Thematic analysis of the data was conducted as per the methodology described by Braun and Clarke.[18] Repeated reading of the transcripts allowed the researchers to achieve a high level of data immersion. The transcripts were coded independently by 2 investigators (JS and $A B$ ) and then themes were identified and agreed upon by all investigators (JS, AB and TW). Any discrepancies in the coding was resolved through discussions between the authors. Quotes were included in the text if they well illustrated the concepts held by a number of participants.

\section{Results}

\section{Quantitative}

Seventy-seven patients were identified as eligible for the study, with 64 consenting to participate, resulting in a response rate of $83 \%$. Twenty-nine (45\%) of these were current smokers, 24 (38\%) were former smokers and 11 (17\%) had never smoked. There was an equal distribution of early (stage I-I $50 \%$ ) and advanced stage cancers (stage III-IV 50\%). Six patients (9\%) were treated with surgery alone, eight (13\%) received adjuvant radiation after surgery and $50(78 \%)$ had primary radiotherapy. Further demographic details of the overall population of current and former/never smokers are described in Table 1. 


\section{Current vs Former/Never Smokers}

The initial analysis compared the baseline characteristics of current smokers with those who were former or never smokers (Table 1). The analysis identified that participants who were current smokers at diagnosis were more likely to live in a rural location $(p=0.015)$, have lower levels of education $(p=$ $0.047)$, and report reduced social and family well-being $(p=0.005)$ when compared with those who were former or never smokers. Current smokers had a higher pack year history (45 vs $26, p=0.005)$ and a lower proportion who were $\mathrm{p} 16$ positive $(35 \%$ vs $66 \%, p=0.013)$, indicating a lower percentage of HPVassociated tumours. There was also an increased proportion of oral cavity cancers in the current smoker group $(31 \%$ vs $9 \%, p=0.021)$.

\section{Smoking Cessation Rates}

Table 2 outlines the continuous and 7-day point prevalence cessation rates at 1 and 3 month follow-up. Only 26 of the 29 current smokers were able to be classified as a ceased or continued smoker. Two participants died before 1 month follow-up and one had not reached 1 month follow-up at the time of analysis. The continuous cessation rates were $54 \%$ at 1 month and $42 \%$ at 3 -month follow up, and the 7day point prevalence cessation rates were $72 \%$ at 1 month and $67 \%$ at 3 month follow-up. This demonstrated that a number of patients were able to actively achieve cessation at some stage in their treatment journey, but relapses were common.

\section{Continuing vs Ceased Smokers}

As highlighted in Table 3, there were 15 patients classified as continuing smokers and 11 as ceased smokers (3 month continuous cessation rate). Patients who continued smoking were more likely to consume more alcohol $(p=0.032)$, be less confident of being able to cease smoking $(p=0.004)$ and be in a lower stage of change (pre-contemplation or contemplation) of the transtheoretical model at baseline ( $p$ $=0.012$ ). There was also higher psychological distress amongst patients who continued to smoke, but this was of borderline significance (K10 19.2 vs 14.7, $\mathrm{p}=0.052$ ).

\section{Qualitative}

The one-on-one interviews were performed with 5 ceased smokers and 10 continued smokers based upon the continuous cessation definition. However, only 6 reported actively smoking at the time of the interview. There were 13 males and 2 females interviewed, with a mean age and pack year history that was similar to that of the overall current smoker cohort. Thematic analysis of the data led to the identification of 5 key themes: The teachable moment of a cancer diagnosis and treatment, willpower and cessation aids, psychosocial environment, relationship with alcohol and marijuana and interaction between health knowledge and beliefs surrounding smoking and cancer. These themes are described below, with pertinent quotes used to illustrate their meaning; further quotes exemplifying each theme are also described in Table 4. Using the health beliefs model as a framework, Figure 2 highlights the 
important perceived benefits and barriers to smoking cessation that were evident throughout the interviews, which will be further explored in the discussion.

\section{Teachable moment of cancer diagnosis and treatment}

This theme encompassed the initial motivating factor that a HNC diagnosis provided, in addition to the role of treatment and its associated side effects in smoking cessation. The role of healthcare practitioners in providing patients with information surrounding smoking cessation was also a significant component of this theme. For patients unable to achieve cessation, there were a number of identifiable periods in which the teachable moment was not observed or unable to be sustained for extended periods of time. However, most patients were able to recount the impact that a HNC diagnosis had on their ability to quit smoking:

"This was just the trigger, whether it was the doctor or the nicotine patches or the operation, or the word cancer, they were all triggers that goes 'oh well, this is what l've been trying to do the last couple of years so let's go"

Irrespective of their smoking status after treatment completion, patients commonly described being able to cease smoking whilst undergoing treatment, particularly for those undergoing radiotherapy. This was outlined as a combination of not wanting to compromise their treatment, being too unwell to smoke because of the side effects of radiotherapy, and the fear of being discovered by the weekly exhaled carbon monoxide readings.

"You got the treatment, you can't smoke. Simple as that. Because every time I had it [treatment], they had that $\mathrm{CO} 2$ puffer. You can't lie. So, what's the use of, you know, trying to hide one a few hours before. And I thought well I'm going to get caught out why just not have it."

The impact of having a smoking-related cancer diagnosis was highlighted by some participants as a motivator for cessation. Patients also identified that a diagnosis of head and neck cancer was a more convincing motivator for contemplating smoking cessation compared with other previous health conditions they had experienced, which included myocardial infarctions and valve replacements.

“Even the heart business [coronary artery bypass graft surgery], after it didn't hurt when I coughed anymore. Within a month or two I would have had one more [smoke] and that's it. But no more now."

\section{Willpower and cessation aids}

Willpower and its interaction with both pharmacological and non-pharmacological aids was identified as an important contributor to achieving cessation. Some patients attempted to cease 'cold turkey' and cited their own willpower as the reason for their success.

"I actually never used anything to stop, apart from willpower"

Conversely, other participants identified their lack of willpower and the requirement for assistance. 
"Some people have got good willpower and that's how they give up smoking and it's cold turkey. Cause their willpower's strong, mine isn't. I need something like an aid to give me a hand not to do it [smoking]. Those patches are like an aid."

A common notion amongst both continued and ceased smokers, was that ceasing smoking is up to the individual, and some were not willing to accept help from external resources such as Quit Line.

“The stubbornness came in, I wouldn't want to use Quit Line, I thought I don't need anyone to help me, I can do this myself."

However, a number of participants were able to identify the helpful nature of the education and motivation given by the healthcare professionals who formed part of their treating team, which overlaps with the teachable moment of a cancer diagnosis.

"If we do this operation, we're really going to need you to give up smoking, and that sort of stuck in my head."

\section{Psychosocial environment}

The role of each patient's psychosocial environment was an integral component of a patient's ability to successfully maintain abstinence. The participants home environment was a major element impacting upon cessation. Being unemployed or not able to work after treatment was identified as another barrier to achieving smoking cessation. One participant with a strong cultural background mentioned the prominent role that their supportive family had played in encouraging smoking cessation.

"They gave me a stern talking, and usually it's the other way around. But this time they all sat me down me son, my girls, my wife. They had no intention of not having me here, so they told me there and then, no more smoking"

However, residing with other smokers was an issue identified by some continued smokers as a barrier to cessation. One participant recalled living with their sister and how this impacted upon their return to smoking after the completion of treatment.

"She [patient's sister] buys rollies and gets me to roll them for her and keep them in a tin and I take a few"

For similar reasons, social isolation was identified as a facilitator to cessation for some patients. These participants were able to identify the facilitatory role of living by themselves with no temptations to smoke. Rurality and spending prolonged periods of time away from their usual place of residence, was a factor that was identified as both a facilitator and a barrier, depending upon the individual. Some patients commented that being away from home for treatment facilitated their smoking cessation, as they were removed from the environment in which their bad habits had been ingrained.

"For me, I'd suggest that it helped [living away from home]. Once again, I go back to that environment, where I was smoking.... So, when you remove yourself from that particular environment and you don't 
bring cigarettes into your new environment it's quite easy to go along with the flow as such and don't smoke."

Conversely, others noted that the stress of being away from home made them return to smoking.

"Yeah that, I didn't like it, being away from home. Yeah it probably made me start again [smoking], I think"

Some participants also described the role that their depression played in a return to smoking, as well as the isolation associated with returning to a rural location after the completion of treatment.

"So, after that [treatment] I still smoked. Everything went downhill, maybe because I did have a bit of bloody depression. Maybe it was because I couldn't get close enough to talk to people here"

\section{Relationship with alcohol and marijuana}

The relationship of alcohol and marijuana use with tobacco smoking and how these behaviours are intrinsically linked was a common theme identified. The majority of patients who continued to smoke were still either consuming alcohol in large quantities or smoking marijuana.

"It's all part and parcel because I'm a chronic alcoholic, and you smoke you drink, you drink you smoke" However, some participants identified that removing the association between alcohol and smoking allowed them to achieve abstinence.

"Sitting there with a glass of wine without a cigarette, I thought, I'm not enjoying this, so I stopped having a glass of wine at 5 o'clock. I removed the temptation"

Some participants who had ceased tobacco smoking identified that they were using marijuana as a substitute for their nicotine use.

"I can't have a cigarette, I'll have a cone [marijuana] instead"

Concerningly, the commencement of marijuana smoking after treatment completion was identified as a trigger for tobacco relapse in some patients.

"Well I've noticed that I am putting the tobacco in with the marijuana, the reason I done that is that the bloody thing won't stay alight without tobacco in it."

Many patients were not able to identify any negative health issues associated with marijuana smoking and perceived it to have minimal effect on their risk of cancer when compared with nicotine.

"Weed [marijuana] would be a lot better than smoking tobacco. You know, it hasn't got the chemicals in it from being treated through the plant in the factory where they put these chemicals in it"

\section{Health knowledge and beliefs of smoking and cancer}


This theme encompassed patient's health knowledge and beliefs surrounding the role of smoking in cancer, smoking cessation and the effects of continued smoking. Most participants with HNC were able to identify that smoking played a role in the formation of their cancer and the harmful effects of continued smoking after their diagnosis. Some patients acknowledged that smoking played a role but identified other factors that they believed may have also contributed to their cancer, such as chemicals from fruit and vegetables or the 'underground mines'. One continued smoker identified that they were more concerned regarding the harmful effects of their occupational exposure than their cigarette smoking.

"I'm more worried about it coming back [the cancer] when I go back using these chemicals [at the underground mines]."

Prior knowledge of addiction and smoking cessation through occupational interventions was demonstrated as a facilitator for some patients. There were two participants (both ceased smokers) who had prior education regarding addictions and withdrawal. Both of these patients stated the role that this had in allowing them to successfully quit.

"We have a tobacco free day [at work] and one of the things I did learn during that time was craving only lasts a minute so if you can keep your fingers busy and drink some water or some mints or something for that minute, once that minute is up that's it, it's done and dusted. So, I had that education behind me as well"

\section{Discussion}

This study is unique in its mixed methods approach and highlights the complex and individual nature of smoking cessation amongst regional Australian head and neck cancer patients. The quantitative results demonstrate that head and neck cancer patients who are smokers at diagnosis are more likely to be from rural locations, have lower levels of education and reduced social and family well-being when compared with participants who were former or never smokers. With the exception of rurality, these findings are consistent with those within the literature, which have demonstrated similar characteristics of this population $[19,20]$. The association between smoking status and rurality has not been studied in a head and neck cancer population previously, but it is known that people from rural Australia have higher rates of tobacco use [21].

The 7-day point prevalence cessation rates of $72 \%$ at 1 month and $67 \%$ at 3 months indicate that the majority of current smokers are able to actively achieve cessation at some stage. However, the lower continuous cessation rates indicate that a number of patients had relapses, with some participants still smoking for the first few weeks of radiotherapy before ceasing, whilst others relapsed after completion of treatment. The discrepancies between the 1 and 3 month follow-up period demonstrate the increased risk of relapse as time from treatment completion increases. This was further explored in the qualitative analysis, where patients often reported relapses in the follow-up period, for a number of reasons. Although a comparison of smoking abstinence rates between studies is challenging due to varying 
definitions, follow-up periods and cessation interventions, the cessation rates identified in this study are comparable with those within the literature. Other studies investigating smoking cessation in head and neck cancer patients found point prevalence abstinence rates of approximately $70 \%[22,23]$, although they have been reported as low as $31 \%$ [24].

The likelihood of achieving smoking cessation was dependent upon a number of factors, with the quantitative results identifying that patients who continued smoking had higher alcohol consumption, were less confident in their ability to cease, were in the lower stages of the transtheoretical model (precontemplation or contemplation) and trended towards higher levels of psychological distress. The 5 qualitative themes identified further explained the barriers and facilitators to smoking cessation and integrated with the quantitative trends demonstrated. This commenced with the 'teachable moment' of a cancer diagnosis and its impact on smoking behaviours. The impact of a cancer diagnosis as a teachable moment for smoking cessation has been highlighted by previous quantitative studies [10, 25]. This was also identified as a prominent theme in the prior qualitative study on smoking cessation in head and neck cancer patients [12]. Healthcare practitioners should therefore be aware of this opportunity to encourage smoking cessation amongst newly diagnosed patients to ensure this window of opportunity is maximised.

Whilst some patients were able to quit 'cold turkey' with only their own individual willpower, this was not sufficient for a number of participants. Patients then required the advice of healthcare professionals and the use of pharmacological aids such as nicotine replacement therapy to enable abstinence. Some patients reported the limited role of external cessation support services such as Quitline and identified that advice provided by the smoking cessation nurse or treating clinician as the major form of assistance. This indicates that the smoking cessation support program may best be overseen and delivered through regular consultations with a dedicated in-hospital healthcare professional, who is familiar with the complexities of cancer care and is able to maximise the teachable moment of a cancer diagnosis. These regular consultations would assist smokers moving further along the stages of change in the transtheoretical model, provide education surrounding the importance of cessation during and after treatment and discuss how potential barriers could be overcome. The integration of smoking cessation advice into standard clinical care for cancer patients has also been recommended in prior studies $[26,27]$.

Participants also identified the interaction between alcohol and marijuana with tobacco smoking and how these behaviours were linked. The quantitative analysis demonstrated that those who continued smoking had higher use of alcohol, with the qualitative analysis allowing an in-depth exploration of this association. Given that continued alcohol use after a HNC diagnosis has also been associated with reduced overall survival [28] and an increased risk of second malignancies [29], there is an added benefit to encouraging cessation of both alcohol and tobacco.

Through the qualitative analysis, the role of marijuana usage in tobacco cessation was explored. This was not investigated in the initial quantitative surveys and would not have been recognised if not for the qualitative analysis, highlighting the importance of using a mixed methods approach. The majority of 
patients reported using marijuana after their treatment, irrespective of whether they ceased or continued using tobacco. For patients who had identified as ceased smokers, a continuation of marijuana smoking raises concerns of a future tobacco relapse, given that these behaviours were previously linked. No prior studies have investigated the interaction of marijuana and tobacco in head and neck cancer patients. Multiple studies in the general population have demonstrated that co-use of marijuana and tobacco is associated with higher nicotine dependence [30,31], which can make cessation challenging. There is a clear requirement for future studies to investigate whether addressing smoking and marijuana cessation will improve rates of abstinence amongst newly diagnosed head and neck cancer patients.

The psychosocial environment was another factor identified as having a major role in the cessation process. Participants who ceased were able to identify protective factors such as a supportive family. For those who did not cease, the psychosocial environment was often a barrier to cessation and included living with other smokers, unemployment and depression. This demonstrates the importance of considering factors such as social environment and mental health when providing cessation advice to patients. The integral role of the social environment in head and neck cancer patients achieving smoking abstinence has also been highlighted previously [19]. This is even more important for head and neck cancer patients in this study given the significant number who live in a rural location where the geographical isolation and reduced access to healthcare services may exacerbate the risk of smoking relapse in the follow-up period.

The mixed methods approach of this study also identified that the predictors of smoking relapses and participants' likelihood of achieving prolonged cessation were consistent with the Health Beliefs Model [32]. Figure 2 presents the Health Beliefs Model modified with the findings of this study. For example, this study found patients who continued smoking were less likely, though not significantly, to perceive head and neck cancer as a fatal disease if not treated. This directly correlates with the health belief model, where perceived severity is a key construct. There were also a number of perceived benefits and barriers to smoking cessation that were identified by the participants, which encompassed multiple qualitative themes. The perceived benefits were either cancer specific, such as reducing the risk of recurrence or general, such as improved quality of life. The perceived barriers were wide-ranging and included a number of the psychosocial determinants outlined previously, as well as other factors such as past negative experiences of cessation attempts.

Given the relatively brief nature of the current cessation intervention utilised in this study, it is plausible that a more comprehensive and sustained, multifactorial cessation program could result in even higher abstinence. This was explored in a recent randomised control trial of head and neck cancer patients, which demonstrated that a comprehensive smoking cessation program involving regular sessions of intensive counselling, pharmacotherapy and contingency management significantly improved cessation rates at 8 weeks [33]. A smoking cessation program that addresses co-morbid risk factors such as alcohol use and depression has also been previously shown to improve cessation rates [24]. This demonstrates the requirement to develop a program that is multifactorial in nature. As highlighted by this 
study, marijuana use is another co-morbid risk factor that has not been investigated previously but should be addressed as part of this comprehensive smoking cessation program.

\section{Limitations}

A limitation of this study was the small sample size, particularly for the analysis on continuing and ceased smokers. Given the trends in the analysis of continuing and ceased smokers it is likely that with a few more participants, a more significant result may be achieved, particularly for the difference in psychological distress between the two groups. Another limitation is that some patients who had no interest in smoking cessation declined to be involved in the study. Therefore, the cessation rate may be lower than reported.

This study also had a relatively short follow-up period and it is possible that some patients may return to smoking further into their follow-up period. These rates of relapse will be determined when analysis is conducted for the 5-year study. For the qualitative analysis, the main limitation is the generalisability of these results given that the participants were all from a North Queensland population. However, the findings are consistent with prior literature and the health beliefs model, indicating that these results may be applicable to other populations.

\section{Conclusion}

This study demonstrates that smoking cessation amongst head and neck cancer patients is a complex process. Whilst the vast majority of HNC patients are able to achieve smoking cessation at some stage, relapses are common. Healthcare workers should be aware of the 'teachable moment' of a cancer diagnosis and the opportunity this presents to encourage smoking cessation, as well as the high risk of relapse in the follow-up period. Future research is required into more comprehensive and multifactorial smoking cessation interventions during and after treatment in the head and neck cancer population. Based on the results of this study, future cessation programs would ideally be delivered by a dedicated inhospital support person via regular sessions that provides education specific to cancer patients, facilitates referrals for behavioural and pharmacological interventions, addresses co-morbid risk factors such as alcohol, depression and marijuana use, and works through each individual's barriers to cessation.

\section{List Of Abbreviations}

HNC - Head and Neck Cancer

HNSCC - Head and Neck Squamous Cell Carcinoma

TTH - The Townsville Hospital

\section{Declarations}




\section{Ethics approval and consent to participate}

Ethics approval for this study was obtained from the Townsville Hospital and Health Service Human Research Ethics Committee (HREC/17/QTHS/223). Study participants provided written consent for inclusion in the study.

\section{Consent for publication}

Not applicable

\section{Availability of data and materials}

The datasets used and/or analysed during the current study are available from the corresponding author on reasonable request

\section{Competing interests}

The authors declare that they have no competing interests

\section{Funding}

The 5-year prospective study from which the quantitative data was derived received a research grant from the Townsville Hospital Study, Education and Research Trust Account (SERTA). This was utilised for assistance with data collection. There was no role of the funding body in the study design, analysis, interpretation of data or writing of the manuscript.

\section{Author's contributions}

JS conducted the data collection (quantitative and qualitative), analysis and writing of the manuscript. TW assisted with data collection of the qualitative component, analysis of the data and drafting of the manuscript. $A B$ was involved with analysis of the qualitative data. VV provided statistical support for the quantitative analysis. MC assisted with data collection (quantitative) and drafting of the manuscript. All authors read and approved the final manuscript.

\section{Acknowledgements}

Not applicable

\section{References}

[1] Hashibe M, Brennan P, Chuang S-C, Boccia S, Castellsague X, Chen C, et al. Interaction between tobacco and alcohol use and the risk of head and neck cancer: pooled analysis in the International Head and Neck Cancer Epidemiology Consortium. Cancer Epidemiol Biomarkers Prev. 2009;18:541-50. 
[2] Cramer JD, Burtness B, Le QT, Ferris RL. The changing therapeutic landscape of head and neck cancer. Nat Rev Clin Oncol. 2019.

[3] Jethwa AR, Khariwala SS. Tobacco-related carcinogenesis in head and neck cancer. Cancer Metastasis Rev. 2017;36:411-23.

[4] Marur S, Forastiere AA. Head and Neck Squamous Cell Carcinoma: Update on Epidemiology, Diagnosis, and Treatment. Mayo Clin Proc. 2016;91:386-96.

[5] Leoncini E, Vukovic V, Cadoni G, Pastorino R, Arzani D, Bosetti C, et al. Clinical features and prognostic factors in patients with head and neck cancer: Results from a multicentric study. Cancer Epidemiol. 2015;39:367-74.

[6] Kobayashi K, Hisamatsu K, Suzui N, Hara A, Tomita H, Miyazaki T. A Review of HPV-Related Head and Neck Cancer. J Clin Med. 2018;7:241.

[7] Smith J, Nastasi D, Tso R, Vangaveti V, Renison B, Chilkuri M. The effects of continued smoking in head and neck cancer patients treated with radiotherapy: A systematic review and meta-analysis. Radiother Oncol. 2019;135:51-7.

[8] Do KA, Johnson MM, Lee JJ, Wu XF, Dong Q, Hong WK, et al. Longitudinal study of smoking patterns in relation to the development of smoking-related secondary primary tumors in patients with upper aerodigestive tract malignancies. Cancer. 2004;101:2837-42.

[9] Jensen $K$, Jensen AB, Grau C. Smoking has a negative impact upon health related quality of life after treatment for head and neck cancer. Oral Oncol. 2007;43:187-92.

[10] Gritz ER, Fingeret MC, Vidrine DJ, Lazev AB, Mehta NV, Reece GP. Successes and failures of the teachable moment. Cancer. 2006;106:17-27.

[11] McCarter K, Martínez Ú, Britton B, Baker A, Bonevski B, Carter G, et al. Smoking cessation care among patients with head and neck cancer: a systematic review. BMJ Open. 2016;6:e012296.

[12] Abdelrahim A, Balmer C, Jones J, Mehanna H, Dunn J. Considerations for a head and neck smoking cessation support programme; A qualitative study of the challenges in quitting smoking after treatment for head and neck cancer. Eur J Oncol Nurs. 2018;35:54-61.

[13] List MA, D'Antonio LL, Cella DF, Siston A, Mumby P, Haraf D, et al. The Performance Status Scale for Head and Neck Cancer Patients and the Functional Assessment of Cancer Therapy-Head and Neck Scale. A study of utility and validity. Cancer. 1996;77:2294-301.

[14] Bush K, Kivlahan DR, McDonell MB, Fihn SD, Bradley KA, Project ftACQI. The AUDIT Alcohol Consumption Questions (AUDIT-C): An Effective Brief Screening Test for Problem Drinking. JAMA Intern Med. 1998;158:1789-95. 
[15] Andrews G, Slade T. Interpreting scores on the Kessler Psychological Distress Scale (K10). Aust NZ J Publ Heal. 2001;25:494-7.

[16] Prochaska JO, Velicer WF. The transtheoretical model of health behavior change. Am J Health Promot. 1997;12:38-48.

[17] Benowitz NL, Jacob P, Ahijevych K, Jarvis MJ, Hall S, LeHouezec J, et al. Biochemical verification of tobacco use and cessation. Nicotine Tob Res. 2002;4:149-59.

[18] Braun V, Clarke V. Using thematic analysis in psychology. Qual Res Psychol. 2006;3:77-101.

[19] Kashigar A, Habbous S, Eng L, Irish B, Bissada E, Irish J, et al. Social environment, secondary smoking exposure, and smoking cessation among head and neck cancer patients. Cancer. 2013;119:2701-9.

[20] Osazuwa-Peters N, Adjei Boakye E, Chen BY, Tobo BB, Varvares MA. Association Between Head and Neck Squamous Cell Carcinoma Survival, Smoking at Diagnosis, and Marital StatusAssociation Between Head and Neck Squamous Cell Carcinoma Survival, Smoking at Diagnosis, and Marital StatusAssociation Between Head and Neck Squamous Cell Carcinoma Survival, Smoking at Diagnosis, and Marital Status. JAMA Otolaryngol Head Neck Surg. 2018;144:43-50.

[21] Tall JA, Brew BK, Saurman E, Jones TC. Implementing an anti-smoking program in rural-remote communities: challenges and strategies. Rural Remote Health. 2015;15:3516.

[22] Gritz ER, Carr CR, Rapkin D, Abemayor E, Chang LJ, Wong WK, et al. Predictors of long-term smoking cessation in head and neck cancer patients. Cancer Epidemiol Biomarkers Prev. 1993;2:261-70.

[23] Cooley ME, Wang Q, Johnson BE, Catalano P, Haddad RI, Bueno R, et al. Factors associated with smoking abstinence among smokers and recent-quitters with lung and head and neck cancer. Lung Cancer. 2012;76:144-9.

[24] Duffy SA, Ronis DL, Valenstein M, Lambert MT, Fowler KE, Gregory L, et al. A tailored smoking, alcohol, and depression intervention for head and neck cancer patients Cancer Epidemiol Biomarkers Prev. 2006;15:2203-8.

[25] Sharp L, Johansson H, Fagerstrom K, Rutqvist LE. Smoking cessation among patients with head and neck cancer: cancer as a 'teachable moment'. Eur J Cancer Care. 2008;17:114-9.

[26] Warren GW, Ward KD. Integration of tobacco cessation services into multidisciplinary lung cancer care: rationale, state of the art, and future directions. Transl Lung Cancer Res. 2015;4:339-52.

[27] de Bruin-Visser JC, Ackerstaff AH, Rehorst H, Retel VP, Hilgers FJ. Integration of a smoking cessation program in the treatment protocol for patients with head and neck and lung cancer. Eur Arch Otorhinolaryngol. 2012;269:659-65. 
[28] Mayne ST, Cartmel B, Kirsh V, Goodwin WJ. Alcohol and Tobacco Use Prediagnosis and Postdiagnosis, and Survival in a Cohort of Patients with Early Stage Cancers of the Oral Cavity, Pharynx, and Larynx. Cancer Epidemiol Biomarkers Prev. 2009;18:3368-74.

[29] Do KA, Johnson MM, Doherty DA, Lee JJ, Wu XF, Dong Q, et al. Second primary tumors in patients with upper aerodigestive tract cancers: joint effects of smoking and alcohol (United States). Cancer Causes Control. 2003;14:131-8.

[30] Wang JB, Ramo DE, Lisha NE, Cataldo JK. Medical marijuana legalization and cigarette and marijuana co-use in adolescents and adults. Drug Alcohol Depen. 2016;166:32-8.

[31] Akbar SA, Tomko RL, Salazar CA, Squeglia LM, McClure EA. Tobacco and cannabis co-use and interrelatedness among adults. Addict Behav. 2019;90:354-61.

[32] Janz NK, Becker MH. The Health Belief Model: a decade later. Health Educ Q. 1984;11:1-47.

[33] Rettig EM, Fakhry C, Hales RK, Kisuule F, Quon H, Kiess AP, et al. Pilot randomized controlled trial of a comprehensive smoking cessation intervention for patients with upper aerodigestive cancer undergoing radiotherapy. Head Neck. 2018;40:1534-47.

\section{Tables}

Table 1: Baseline Characteristics - Current vs Former/Never Smokers 


\begin{tabular}{|c|c|c|c|c|}
\hline & Total & $\begin{array}{l}\text { Current } \\
\text { Smokers } \\
\end{array}$ & $\begin{array}{c}\text { Former/Never } \\
\text { Smokers }\end{array}$ & $\begin{array}{c}\mathrm{p} \\
\text { value }\end{array}$ \\
\hline \multicolumn{5}{|l|}{ Patient Demographics } \\
\hline $\mathrm{N}$ & 64 & $29(45.3 \%)$ & $35(54.7 \%)$ & NA \\
\hline Age & $60.1 \pm 8.3$ & $60.1 \pm 7.6$ & $60.2 \pm 8.9$ & 0.950 \\
\hline Male & $54(84.4 \%)$ & $24(82.8 \%)$ & $30(85.7 \%)$ & 0.746 \\
\hline $\begin{array}{l}\text { Aboriginal or Torres Strait } \\
\text { Islander }\end{array}$ & $3(4.7 \%)$ & $2(6.9 \%)$ & $1(2.9 \%)$ & 0.447 \\
\hline Rural Location* & $27(42.2 \%)$ & $17(58.6 \%)$ & $10(28.6 \%)$ & 0.015 \\
\hline \multicolumn{5}{|l|}{ Tumour Characteristics } \\
\hline p16+ & $33(51.6 \%)$ & $10(34.5 \%)$ & $23(65.7 \%)$ & 0.013 \\
\hline Stage I-II (Early) & $32(50 \%)$ & $12(41.4 \%)$ & $20(57.1 \%)$ & \multirow{2}{*}{0.209} \\
\hline Stage III-IV (Advanced) & $32(50 \%)$ & $17(58.6 \%)$ & $15(42.9 \%)$ & \\
\hline \multicolumn{5}{|l|}{ Cancer Location** } \\
\hline Oral Cavity & $12(18.8 \%)$ & $9(31.0 \%)$ & $3(8.6 \%)$ & 0.021 \\
\hline Oropharynx & $38(59.4 \%)$ & $14(48.3 \%)$ & $24(68.6 \%)$ & 0.098 \\
\hline Larynx & $12(18.8 \%)$ & $5(17.2 \%)$ & $7(20.0 \%)$ & 0.786 \\
\hline \multicolumn{5}{|l|}{ Treatment Modality } \\
\hline Surgery only & $6(9.4 \%)$ & $4(13.8 \%)$ & $2(5.7 \%)$ & \multirow{3}{*}{0.020} \\
\hline Adjuvant RT & $8(12.5 \%)$ & $7(24.1 \%)$ & $1(2.9 \%)$ & \\
\hline RT only & $50(78.1 \%)$ & $18(62.1 \%)$ & $32(91.4 \%)$ & \\
\hline \multicolumn{5}{|l|}{ Education } \\
\hline Up to Year 10 & $31(48.4 \%)$ & $18(62.1 \%)$ & $13(37.1 \%)$ & \multirow{2}{*}{0.047} \\
\hline $\begin{array}{l}\text { Year } 12 \text { and Higher (TAFE, } \\
\text { University) }\end{array}$ & $33(51.6 \%)$ & $11(37.9 \%)$ & $22(62.9 \%)$ & \\
\hline \multicolumn{5}{|l|}{ FACT- Quality of Life } \\
\hline Section 1 (Physical Well-Being) & $23(7.0)$ & $23(7.0)$ & $23(8.0)$ & 0.802 \\
\hline $\begin{array}{l}\text { Section } 2 \text { (Social/Family Well- } \\
\text { Being) }\end{array}$ & $23.5(9.8)$ & $20(12.5)$ & $24.5(5.0)$ & 0.005 \\
\hline Section 3 (Emotional Well-Being) & $18(5.0)$ & $18(4.5)$ & $18(5.0)$ & 0.340 \\
\hline Section 4 (Functional Well-Being) & $19(9.8)$ & $18(9.0)$ & $19(10.0)$ & 0.410 \\
\hline Section 5 (Additional Concerns) & $31(11.8)$ & $31(12.0)$ & $31(12.0)$ & 0.584 \\
\hline Total & $\begin{array}{l}107.9 \pm \\
21.6\end{array}$ & $106.1 \pm 18.9$ & $109.4 \pm 23.8$ & 0.539 \\
\hline \multicolumn{5}{|l|}{ Smoking, Alcohol and Depression } \\
\hline Smoking Pack Years*** & $42(28.8)$ & $45(24.7)$ & $26(29.5)$ & 0.005 \\
\hline AUDIT-C & $4.5(6.0)$ & $6(7.0)$ & $\frac{12.04}{4(6.0)}$ & 0.322 \\
\hline K10 Score & $17(9.0)$ & $16(7.0)$ & $17(9.0)$ & 0.665 \\
\hline
\end{tabular}

*Rural Location - Living outside of Townsville, Cairns or Mackay

**Only 3 most common cancer locations listed, statistical analysis performed by comparing stated location vs 'other location'

***Only amongst participants with a smoking history (never smokers excluded)

Table 2: Smoking Cessation Rates 


\begin{tabular}{|c|c|c|c|}
\hline \multicolumn{2}{|c|}{ Continuous Cessation } & \multicolumn{2}{c|}{ 7-Day Point Prevalence Cessation } \\
\hline 1 Month Follow-Up & 3 Month Follow-Up & 1 Month Follow-Up & 3 Month Follow-Up \\
\hline $14 / 26(53.8 \%)$ & $11 / 26(42.3 \%)$ & $18 / 25(72.0 \%)$ & $16 / 24(66.7 \%)$ \\
& & & \\
\hline
\end{tabular}

Footnote - Only 26 of the 29 current smokers were able to be classified as a ceased or continued smoker. Two patients died before 1 month follow-up and 1 patient had not reached 1 month follow-up at the time of analysis. One patient consented to the study and continued smoking in the first week of treatment but declined further involvement in the study, so their point prevalence cessation could not be determined. Another participant was not able to have point prevalence calculated for 3 month follow-up as they died between 1 and 3 month follow-up.

Table 3: Continuing vs Ceased Smokers 


\begin{tabular}{|c|c|c|c|}
\hline & Continuing Smokers & Ceased Smokers & $\begin{array}{c}\mathrm{p} \\
\text { value }\end{array}$ \\
\hline \multicolumn{4}{|l|}{ Patient Demographics } \\
\hline $\mathrm{N}$ & $15(57.7 \%)$ & $11(42.3 \%)$ & NA \\
\hline Age & $59.9 \pm 4.1$ & $60.7 \pm 9.3$ & 0.818 \\
\hline Male & $13(86.7 \%)$ & $9(81.8 \%)$ & 0.735 \\
\hline Rural Location* & $8(57.1 \%)$ & $6(42.9 \%)$ & 0.951 \\
\hline \multicolumn{4}{|l|}{ Education } \\
\hline Up to Year 10 & $11(73.3 \%)$ & $6(54.5 \%)$ & \multirow[t]{2}{*}{0.419} \\
\hline $\begin{array}{l}\text { Year } 12 \text { and Higher (TAFE, } \\
\text { University) }\end{array}$ & $4(26.7 \%)$ & $5(45.5 \%)$ & \\
\hline \multicolumn{4}{|l|}{ Tumour Characteristics } \\
\hline p16+ & $7(46.7 \%)$ & $3(27.3 \%)$ & \multirow{3}{*}{ 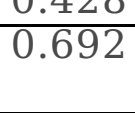 } \\
\hline Stage I-II (Early) & $6(40.0 \%)$ & $6(54.5 \%)$ & \\
\hline Stage III - IV (Advanced) & $9(64.3 \%)$ & $5(45.5 \%)$ & \\
\hline \multicolumn{4}{|l|}{ FACT - Quality of Life } \\
\hline Total** & $106.8 \pm 21.3$ & $109.3 \pm 15.4$ & 0.748 \\
\hline \multicolumn{4}{|l|}{ Alcohol and Psychological Distress } \\
\hline AUDIT-C & $8.5(6.0)$ & $4(5.0)$ & 0.032 \\
\hline K10 & $19.2 \pm 7.1$ & $14.7 \pm 3.4$ & 0.052 \\
\hline \multicolumn{4}{|l|}{ Smoking Behaviours } \\
\hline Pack Year History & $50(56.0)$ & $43(20.3)$ & 0.164 \\
\hline Initial Stage of Change & $\begin{array}{c}\text { Pre-Contemplation: } 2 \\
(13.3 \%) \\
\text { Contemplation: } 6 \\
(40.0 \%) \\
\text { Preparation: } 5 \\
\text { (33.3\%) } \\
\text { Action: } 2(13.3 \%) \\
\end{array}$ & $\begin{array}{c}\text { Pre-Contemplation: } \\
0 \text { (0\%) } \\
\text { Contemplation: } 2 \\
(18.2 \%) \\
\text { Preparation: } 2 \\
(18.2 \%) \\
\text { Action: } 7(63.6 \%)\end{array}$ & 0.012 \\
\hline $\begin{array}{l}\text { Time to First Cigarette } \\
(<30 \text { mins })\end{array}$ & $13(86.7 \%)$ & $8(72.7 \%)$ & 0.620 \\
\hline Prior Cessation Attempts & $11(73.3 \%)$ & $9(81.8 \%)$ & 1.0 \\
\hline Likert-Scal & Questions (Scale of 1 to & ) & \\
\hline $\begin{array}{l}\text { Perception of HNC as a fatal disease } \\
\text { if not treated }\end{array}$ & $\begin{array}{c}1: 0(0 \%) \\
2: 3(20.0 \%) \\
3: 2(13.3 \%) \\
4: 10(66.7 \%) \\
\end{array}$ & $\begin{array}{c}1: 0(0 \%) \\
2: 0(0 \%) \\
3: 1(9.1 \%) \\
4: 10(90.9 \%) \\
\end{array}$ & 0.106 \\
\hline Perception of HNC as treatable & $\begin{aligned} & 1: 0(0 \%) \\
& 2: 0(0 \%) \\
& 3: 8(53.3 \%) \\
& 4: 7(46.7 \%) \\
&\end{aligned}$ & $\begin{array}{c}1: 0(0 \%) \\
2: 1(9.1 \%) \\
3: 3(27.3 \%) \\
4: 7(63.6 \%) \\
\end{array}$ & 0.734 \\
\hline Likely to give up smoking & $\begin{aligned} 1: 0(0 \%) \\
2: 2(13.3 \%) \\
3: 7(46.7 \%) \\
4: 6(40.0 \%) \\
\end{aligned}$ & $\begin{aligned} & 1: 0(0 \%) \\
& 2: 0(0 \%) \\
& 3: 0(0 \%) \\
& 4: 11(100 \%)\end{aligned}$ & 0.004 \\
\hline Worried that cancer will recur & $\begin{aligned} 1: 0 & (0 \%) \\
2: 3 & (20.0 \%) \\
3: 5 & (33.3 \%) \\
4: 7 & (46.7 \%)\end{aligned}$ & $\begin{array}{c}1: 1(9.1 \%) \\
2: 0(0 \%) \\
3: 5(45.5 \%) \\
4: 5(45.5 \%)\end{array}$ & 0.985 \\
\hline
\end{tabular}

Table 4: Quotes exemplifying each of the 5 qualitative themes 


\begin{tabular}{|c|c|}
\hline 'heme & Quotes \\
\hline $\begin{array}{l}\text { lable } \\
\text { ənt of a } \\
\text { sr } \\
\text { losis and } \\
\text { ment }\end{array}$ & $\begin{array}{l}\text { "With the treatment and all that it has like triggered something because I } \\
\text { have tried giving up [smoking] heaps of times. The cancer triggered a lot of } \\
\text { things in my head. You know I want to eat properly, lose weight, be more } \\
\text { active and do something with my life." } \\
\text { "When they told me, I had throat cancer. I thought well I got to give up" } \\
\text { "Everything revolves around the cancer and the treatment. Smoking is not } \\
\text { insistent anymore. Everything is new. I don't drink coffee anymore, I just } \\
\text { drink black tea because of the taste, nothing to do with smoking. And I } \\
\text { always got up in the morning and had a coffee and a cigarette." }\end{array}$ \\
\hline $\begin{array}{l}\text { ower and } \\
\text { ttion aids }\end{array}$ & $\begin{array}{l}\text { "You blokes you can go gather all this information and its good, but it's } \\
\text { really me that needs to give up. It's me that makes that choice" } \\
\text { "The willpower was the main thing that made me give it up. I only have to } \\
\text { think of my chemo and what I've gone through, that makes me don't want to } \\
\text { smoke" }\end{array}$ \\
\hline $\begin{array}{l}\text { ionship } \\
\text { alcohol } \\
\text { narijuana }\end{array}$ & $\begin{array}{l}\text { "I used to have tobacco with the dope, and I decided at some stage if I } \\
\text { wanted to give up smoking, I wasn't going to give up dope smoking" } \\
\text { "The smokes can go, but the beer's gotta stay there, gotta give me } \\
\text { something to do." }\end{array}$ \\
\hline $\begin{array}{l}\text { Iosocial } \\
\text { onment }\end{array}$ & $\begin{array}{l}\text { "I was really happy about that, it was only after I got home and I got better, } \\
\text { and stronger and started eating full meal feeds again, solids. That's when I } \\
\text { sort of went back to smoking, having a durry here and there you know. Its } \\
\text { only cause I bummed off me sister" } \\
\text { "I live by myself. I thought about that the other day, if someone else was } \\
\text { smoking in the house. I thought you couldn't do that, having the smell of } \\
\text { smoke and having someone around you having a cigarette, the temptations } \\
\text { would be huge to have one yourself." } \\
\text { "I'm not working at all, and that's another thing if I was working that I } \\
\text { wouldn't be worried because no one likes to smoke at work, it's sort of like } \\
\text { a bad thing now isn't it" }\end{array}$ \\
\hline
\end{tabular}

Page 21/ 24 


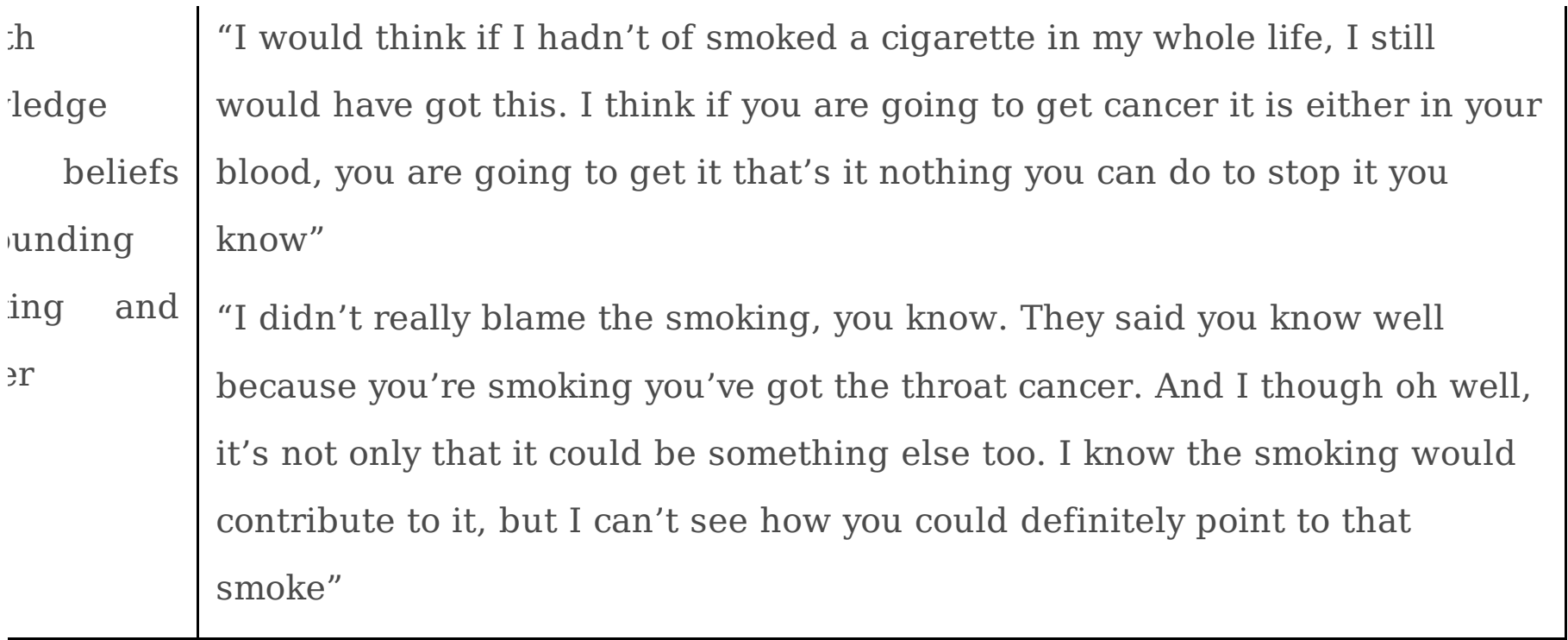

\section{Figures}



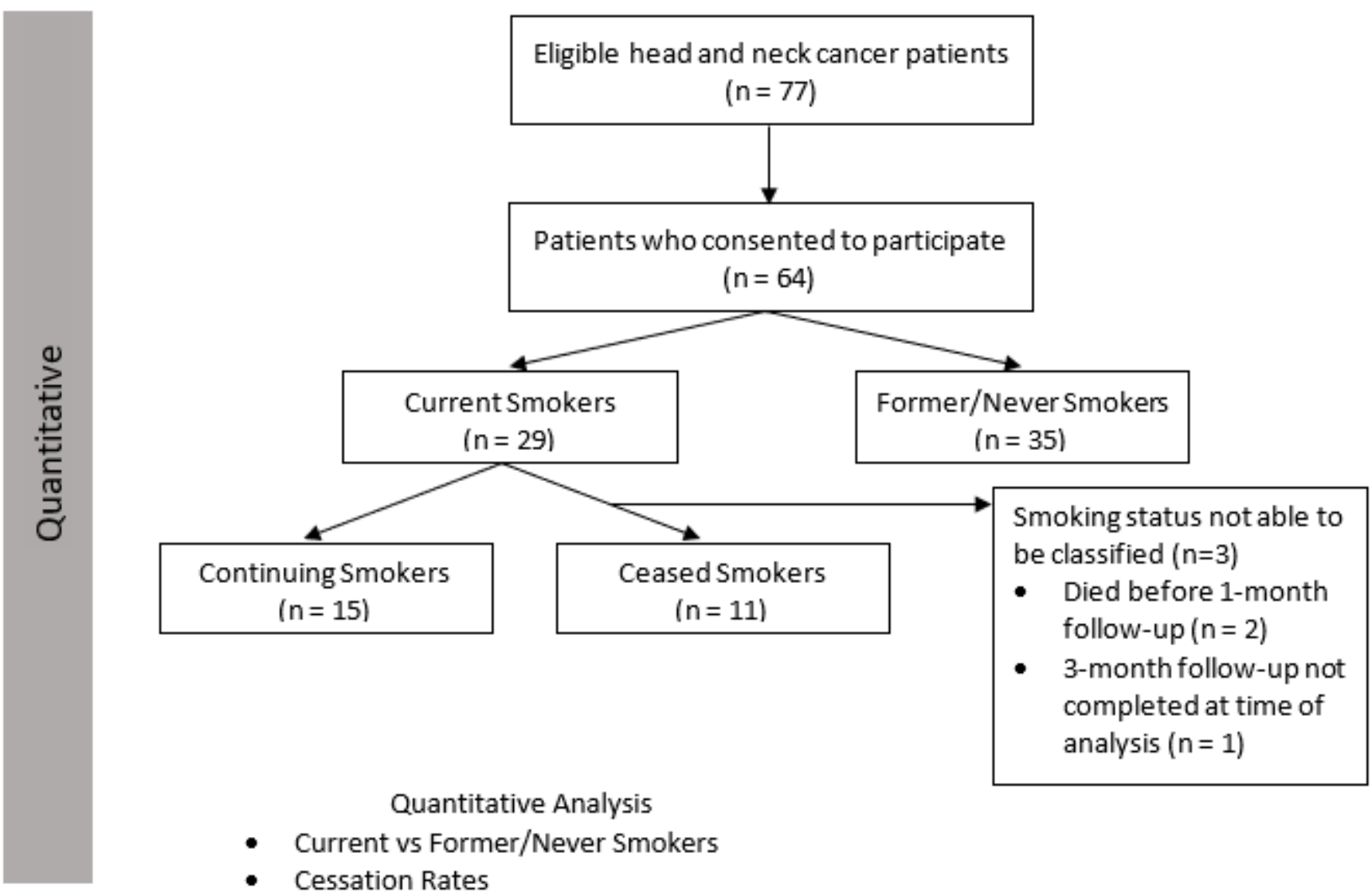

Quantitative Analysis

- Current vs Former/Never Smokers

- Cessation Rates

- Continuing vs Ceased Smokers

One-on-one semi-structured interviews $(n=15)$

- Explaining trends in quantitative data \& exploring barriers and facilitators to smoking cessation

\section{Figure 1}

Overview of the explanatory sequential mixed methods design of this study and the number of participants for each analysis. 


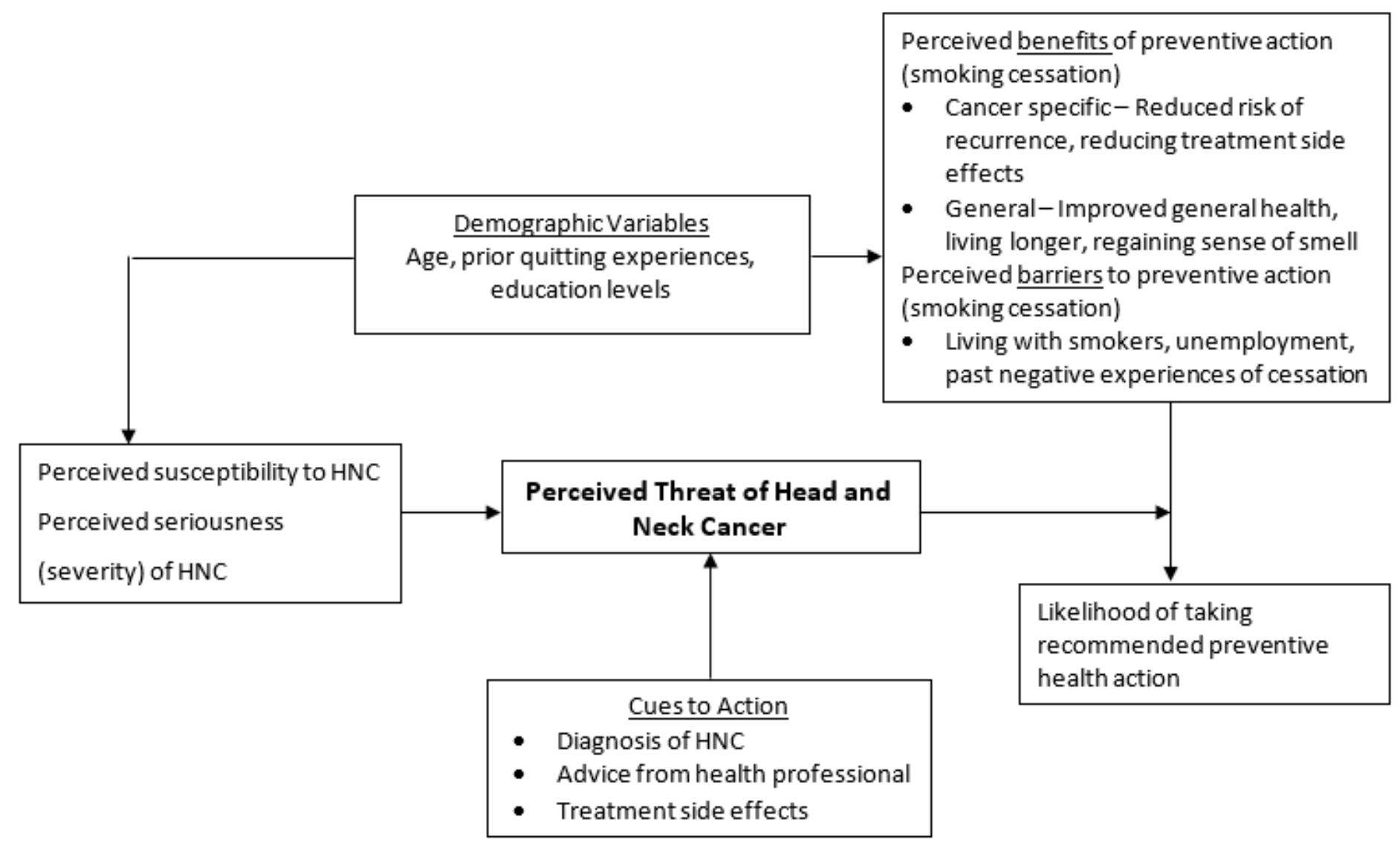

Figure 2

Overview of how smoking cessation in head and neck cancer patients follows the Health Beliefs Model, with specific examples from the findings of this study. A modified diagram from Janz and Becker27

\section{Supplementary Files}

This is a list of supplementary files associated with this preprint. Click to download.

- Supplementary1.pdf

- Supplementary2.pdf 